\title{
Article \\ Physical Activity as a Predictor of the Level of Stress and Quality of Sleep during COVID-19 Lockdown
}

\author{
Anna Lipert ${ }^{1, *(1)}$, Remigiusz Kozłowski ${ }^{2}\left({ }^{\circ}\right.$, Dariusz Timler ${ }^{3}{ }^{(0}$, Michał Marczak ${ }^{4}$, Kamila Musiał $^{1}$, \\ Paweł Rasmus ${ }^{5}$, Karolina Kamecka ${ }^{4}$ and Anna Jegier ${ }^{1}$ \\ 1 Department of Sports Medicine, Medical University of Lodz, 92-213 Lodz, Poland; \\ kamila.musial@umed.lodz.pl (K.M.); anna.jegier@umed.lodz.pl (A.J.) \\ 2 Center of Security Technologies in Logistics, Faculty of Management, University of Lodz, \\ 90-237 Lodz, Poland; remigiusz.kozlowski@wz.uni.lodz.pl \\ 3 Department of Emergency Medicine and Disaster Medicine, Medical University of Lodz, 92-213 Lodz, Poland; \\ dariusz.timler@umed.lodz.pl \\ 4 Department of Management and Logistics in Healthcare, Medical University of Lodz, 90-131 Lodz, Poland; \\ michal.marczak@umed.lodz.pl (M.M.); karolina.kamecka@stud.umed.lodz.pl (K.K.) \\ 5 Department of Medical Psychology, Medical University of Lodz, 90-131 Lodz, Poland; \\ pawel.rasmus@umed.lodz.pl \\ * Correspondence: anna.lipert@umed.lodz.pl
}

Citation: Lipert, A.; Kozłowski, R.; Timler, D.; Marczak, M.; Musiał, K.; Rasmus, P.; Kamecka, K.; Jegier, A. Physical Activity as a Predictor of the Level of Stress and Quality of Sleep during COVID-19 Lockdown. Int. J Environ. Res. Public Health 2021, 18, 5811. https://doi.org/10.3390/ ijerph18115811

Academic Editors: Izabella Lecka, Sally Brailsford, Józef Haczyński and Remigiusz Kozlowski

Received: 15 April 2021

Accepted: 25 May 2021

Published: 28 May 2021

Publisher's Note: MDPI stays neutral with regard to jurisdictional claims in published maps and institutional affiliations.

Copyright: (c) 2021 by the authors. Licensee MDPI, Basel, Switzerland. This article is an open access article distributed under the terms and conditions of the Creative Commons Attribution (CC BY) license (https:// creativecommons.org/licenses/by/ $4.0 /)$.

\begin{abstract}
Background: The coronavirus pandemic and the government restrictions significantly disturbed the daily functioning of people, thereby influencing healthy behaviors, such as physical activity-the core indicator of well-being. This study evaluates the associations between physical activity (PA), the level of stress and quality of sleep during the COVID-19 pandemic lockdown. Methods: An online survey was distributed during the governmental lockdown in April 2020 and included measures for assessing physical activity, stress and sleep. The surveyed participants included all adults aged 18 years and over. The final data were collected from the 1959 respondents using: International Physical Activity Questionnaire-Short Form (IPAQ-SF), Perceived Stress Scale (PSS) and Pittsburgh Sleep Quality Index (PSQI). Findings: Almost half of the respondents indicated a low level of PA, performing only $60 \mathrm{~min}$ of PA daily. Most of the participants reported a moderate or high level of stress (57\% and $29 \%$, respectively) and $64 \%$ of them reported poor quality of sleep. People with low levels of stress performed on average $85.1 \mathrm{~min} /$ day of walking (WPA), $40.9 \mathrm{~min} /$ day of moderate PA (MPA) or $52.6 \mathrm{~min} /$ day of vigorous PA (VPA). People with good quality of sleep performed $82.9 \mathrm{~min} /$ day of WPA, $43.6 \mathrm{~min} /$ day MPA and $40.5 \mathrm{~min} /$ day VPA. Interpretation: The results from the study indicate that the volume of daily PA may be a predictor of the level of stress and sleep quality in adults during the COVID-19 pandemic lockdown. To retain a low level of stress and good quality of sleep, a lifestyle that allows to achieve a moderate level of physical activity should be maintained. The optimal daily dose of PA is at least $70 \mathrm{~min}$ per day, involving different intensities.
\end{abstract}

Keywords: pandemic; physical activity; quality of sleep; stress in COVID

\section{Introduction}

Since December 2019, the world community has been experiencing a pandemic from a novel coronavirus SARS-CoV-2, known as COVID-19 [1,2]. The scale of the pandemic has resulted in the worldwide concern over the extent to which human health and well-being have been affected as a result of the changes in people's everyday life [3], limiting the opportunities to perform physical activity (PA).

Physical activity is at the core of health and well-being and the benefits of PA, such as lower levels of stress, anxiety and depressed mood, are well-known. With the enactment of social isolation and physical distancing restrictions and other actions aimed to reduce 
the COVID-19 pandemic, the usual places for physical activities, e.g., gyms and outdoor recreation facilities, were no longer accessible. Although there are people who have their own strong inner need for physical activity, most of the population probably reduced their PA due to the absence of social support or concerns for contracting the virus in an outdoor environment [3].

During the COVID-19 pandemic, there has been widespread emotional distress caused by the outbreak itself or the measures taken to bring it under control [4,5]. Moreover, many people changed the form of fulfilling their work obligations or even lost their source of income, which may additionally augment psychological distress for both men and women [6]. Data from China suggests that about $25 \%$ of the general population have experienced moderate to severe levels of stress- or anxiety-related symptoms in response to COVID-19 [7,8]. Facing stressful situations may cause symptoms such as sleep suppression and increased wakefulness, thus increasing the occurrence of insomnia, daytime sleepiness, nightmares and daytime dysfunction [9]. Additionally, sleep disturbances are prevalent, especially in individuals who are forced into medical isolation [10].

Sleep is an indispensable physiological process in maintaining physical health [3] and an integral part of proper human functioning [11]. Having a good quality of sleep is important in strengthening immunity [12], hence any sleep disturbances being a consequences of stress induced by the COVID-19 pandemic may increase susceptibility to infection or compromise recovery in the event of an infection [13].

Early evidence gathered during the COVID-19 outbreak suggests positive associations between increased physical activity, physical health [3] and lower psychological distress $[14,15]$. However, more detailed exploration of the COVID-19 pandemic lockdown and thus restricted physical activity and its impact on health may help direct future public health policy to maintain well-being of the community. Therefore, the present study aims to evaluate associations between the volume of physical activity and the level of stress and sleep quality due to the implementation of social isolation rules during the COVID-19 pandemic lockdown.

\section{Material and Methods}

\subsection{Study Design and Data Collection}

Data was collected form 1959 respondents. An anonymous online survey was hosted on the survey platform Google and distributed using social media sources (Facebook, Twitter), with the help of popular national Influencers via their web pages and via institutional sources, including email. The surveyed participants included all adults aged 18 years and over. Participation in the study was voluntary and did not involve any form of gratification. Completing the questionnaire was anonymous and equivalent to agreeing to participate in the study, so the relevant University Human Ethics Committee decided to exempt it from the obligation of their approval. Data collection occurred during the governmental lockdown between 1 and 14 April 2020. The study meets the ethical standards of the journal.

At the time of the survey distribution, the situation in the country required significant personal distancing, lockdown and travel restrictions. No person was allowed to leave the house except for a journey to work or necessary shopping. People under 18 years old were allowed to leave the house only under the supervision of an adult. Social distancing measures included keeping a minimum $2 \mathrm{~m}$ distance between people, a ban on any public gatherings and a limited number of people in the shops and on public transport. There were also designated hours, between 10 and $12 \mathrm{am}$, for seniors in the shops when nobody under 65 years of age was allowed to enter. Lockdown restrictions also included the closure of restaurants and bars, hotels, parks and beaches, hairdressers and beauty studios. Schools and universities were closed, with face-to-face teaching transitioned to online learning. Travel within towns and cities was only permitted for essential work or workers, or to access essential services such as medical or healthcare. 
Socio-demographic data was collected using a self-made questionnaire in which the questions were selected to get the relevant information influencing primarily the physical activity level, the quality of sleep and stress level.

The physical activity (PA) level was self-reported using the International Physical Activity Questionnaire-Short Form (IPAQ-SF), which estimates the last 7 days' activity [16,17]. IPAQ-SF comprises items assessing the frequency and duration of physical activity in three ranges of intensity: vigorous physical activity (VPA $=8.0$ metabolic equivalent (METs)), moderate physical activity (MPA $=4.0 \mathrm{METs}$ ) and low physical activity, determined as walking (WPA = 3.3 METs) undertaken across a set of domains, including leisure time, household activities and gardening (yard), and work-related and transport-related activities during a typical week of their life. The final results of IPAQ were proceeded in accordance with the IPAQ scoring protocol guideline $[17,18]$ and presented as the total count of minutes of physical activity per day.

The quality and patterns of sleep for adults was measured by the Pittsburgh Sleep Quality Index (PSQI). It differentiates "poor" from "good" sleep quality by measuring the following seven areas (components): subjective sleep quality, sleep latency, sleep duration, habitual sleep efficiency, sleep disturbances, use of sleeping medications and daytime dysfunction over the last month. A total score of " 5 " or more is indicative of poor sleep quality. The evidence synthesis for the PSQI showed its strong reliability and validity in a variety of samples, suggesting that the tool fulfils its intended utility [19].

The level of stress was measured by the Perceived Stress Scale (PSS), which is a validated $[20,21]$ classic stress assessment instrument originally developed in 1983 . The questions in this scale refer to feelings and thoughts during the last month. Individual scores on the PSS can range from 0 to 40, with higher scores indicating higher levels of perceived stress: the range between 0 and 13 points means a low level of stress (LLS), the score between 14 and 26 points indicates a moderate level of stress (MLS) and the range of 27-40 points means a high level of stress (HLS).

\subsection{Statistical Analysis}

Statistical analyses were performed using the STATISTICA (StatSoft, Inc. 2011, Statsoft Polska Sp. z o.o., Lodz, Poland, version 10, www.statsoft.com, accessed on 23 March 2015). When the Shapiro-Wilk test revealed that data were normally distributed, parametric tests were performed and the statistical analysis was performed by Student's $t$-test. When data was not normally distributed, non-parametric tests were used. The analysis of variance (ANOVA) was also performed to observe the relationship between time of PA, the level of stress and the quality of sleep. To compare the percentage of categorical variables (level of PA, level of stress, quality of sleep), the chi-square test was performed. The relationship between physical activity and stress (PA min/day and PSS score) was conducted using the Pearson correlation. All confidence intervals (CIs) are presented as 95\% CI. Significant differences were accepted for all analyses at the level of $p<0.05$.

\section{Results}

\subsection{Characteristics of the Participants}

The general characteristics of the study participants can be found in Tables 1-3 and Figure 1. A large group of the participants was represented by people living in a city of over 100,000 citizens and declaring that they performed office work. However, half of them did not work during the pandemic for such reasons as vacation, dismissal or job loss. Most of the study participants had to comply with the restrictions resulting from government regulations. The study participants reported their habitual physical activity of $49.32 \pm 38.01 \mathrm{~min} /$ day on average. Almost half of the study participants had a low level of PA, being physically active for only $24.30 \pm 16.74 \mathrm{~min} /$ day in comparison to people with moderate, $69.82 \pm 23.82 \mathrm{~min} /$ day, and high levels of PA, $116.12 \pm 27.19 \mathrm{~min} /$ day, with $p<0.001$ (Table 3 and Figure 1). Generally, most of the study participants were characterized by moderate or high levels of stress and usually poor quality of sleep (Table 2). 
Table 1. The main socio-demographic variables characterizing the study group $(n=1959)$.

\begin{tabular}{|c|c|}
\hline Socio-Demographic Variables & $\begin{array}{l}\text { All the Study Group } \\
n(\%)\end{array}$ \\
\hline \multicolumn{2}{|l|}{ Sex } \\
\hline Female & $1681(85.8)$ \\
\hline Male & $278(14.2)$ \\
\hline \multicolumn{2}{|l|}{ Place of living } \\
\hline City $>100,000$ citizens & $999(51.0)$ \\
\hline City $20-100,000$ citizens & $379(19.3)$ \\
\hline Town $<20,000$ citizens & $180(9.2)$ \\
\hline Village & $401(20.5)$ \\
\hline \multicolumn{2}{|l|}{ Type of work } \\
\hline Office work & 1149 (58.6) \\
\hline Physical work & $445(22.7)$ \\
\hline Not applicable & $366(18.7)$ \\
\hline \multicolumn{2}{|l|}{ Occupational status } \\
\hline Unemployed & $421(21.5)$ \\
\hline Employed & $1159(59.1)$ \\
\hline Retirement & $20(1.0)$ \\
\hline Student & $359(18.4)$ \\
\hline \multicolumn{2}{|l|}{ Form of work during pandemic } \\
\hline Not working/unemployed & $976(49.8)$ \\
\hline Remote work & $639(32.6)$ \\
\hline In the workplace & $344(17.6)$ \\
\hline \multicolumn{2}{|l|}{ Form of lockdown } \\
\hline Governmental restrictions & $1538(78.5)$ \\
\hline Quarantine & $23(1.2)$ \\
\hline $\begin{array}{l}\text { No restrictions because of the type of occupation } \\
\text { (medical staff, etc.) }\end{array}$ & $398(20.3)$ \\
\hline
\end{tabular}

Table 2. The characteristics of the study participants regarding the volume of PA, level of stress and quality of sleep $(n=1959)$.

\begin{tabular}{cc}
\hline & $\begin{array}{c}\text { All the Study Group } \\
\boldsymbol{n} \mathbf{( \% )}\end{array}$ \\
\hline Level of PA during pandemic lockdown & \\
Low PA & $957(49)$ \\
Moderate PA & $750(38)$ \\
High PA & $252(13)$ \\
Level of stress during pandemic lockdown & $277(14)$ \\
Low (LLS) & $1118(57)$ \\
Moderate (MLS) & $564(29)$ \\
High (HLS) & $1256(64)$ \\
Quality of sleep during pandemic lockdown & $703(36)$ \\
Poor &
\end{tabular}


Table 3. Time of physical activity, level of stress and quality of sleep in the study population $(n=1956)$ according to the level of PA.

\begin{tabular}{ccccc}
\hline & $\begin{array}{c}\text { All the Study } \\
\text { Group }\end{array}$ & $\begin{array}{c}\text { Low Level } \\
\text { of PA }\end{array}$ & $\begin{array}{c}\text { Moderate } \\
\text { Level of PA }\end{array}$ & $\begin{array}{c}\text { High Level } \\
\text { of PA }\end{array}$ \\
\cline { 2 - 5 } & \multicolumn{4}{c}{ Mean $( \pm$ SD) } \\
\hline Total PA (min/day) & $49.32 \pm 38.01$ & $24.30 \pm 16.74 *$ & $69.82 \pm 23.82 \#$ & $116.12 \pm 27.19$ \\
Walking PA (min/day) & $30.82 \pm 33.01$ & $16.00 \pm 16.25$ & $42.06 \pm 35.63$ & $65.77 \pm 41.73$ \\
Moderate PA(min/day) & $7.98 \pm 9.66$ & $4.98 \pm 7.62$ & $11.23 \pm 10.50$ & $12.29 \pm 10.81$ \\
Vigorous PA (min/day) & $9.57 \pm 12.14$ & $2.96 \pm 5.22$ & $15.93 \pm 12.85$ & $18.71 \pm 14.76$ \\
PSSQ (in points) & $22.06 \pm 7.36$ & $22.68 \pm 7.37$ & $21.63 \pm 7.25$ & $20.96 \pm 7.47$ \\
GPQS (in points) & $8.23 \pm 3.29$ & $8.26 \pm 2.71$ & $8.13 \pm 2.74$ & $8.36 \pm 5.82$ \\
\hline
\end{tabular}

* $p<0.001$ Low vs. High; ${ }^{\#} p<0.05$ Moderate vs. High.
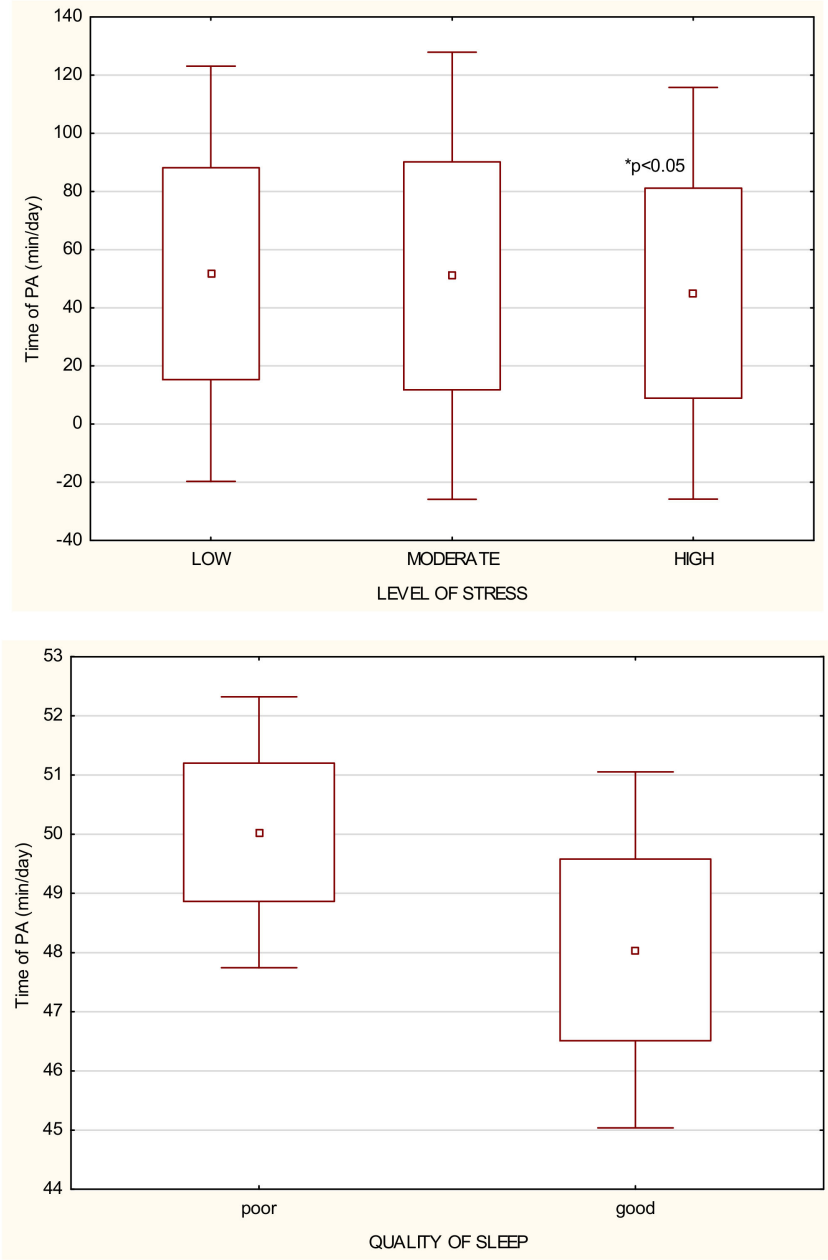

Figure 1. The relationship between the time of PA per day performed by the study participants $(n=1956)$, the level of stress and the quality of sleep.

\subsection{Level of Stress in Relation to Physical Activity during Lockdown}

In the whole study group, most of the participants had a moderate or high level of stress (Table 2). However, there were fewer people with a high level of stress among those who were classified as moderately or highly active (Figure 2). People with the high level of stress performed physical activity for only $44.99 \pm 36.10 \mathrm{~min} /$ day, while people with moderate and low levels of stress performed $50.99 \pm 39.21$ and $51.71 \pm 36.43 \mathrm{~min} /$ day, respectively (Figure 1 and Table 4). Generally, it was observed that if the level of physical activity was higher, the stress level was significantly reduced $(p<0.001)$ (Figure 3$)$. 


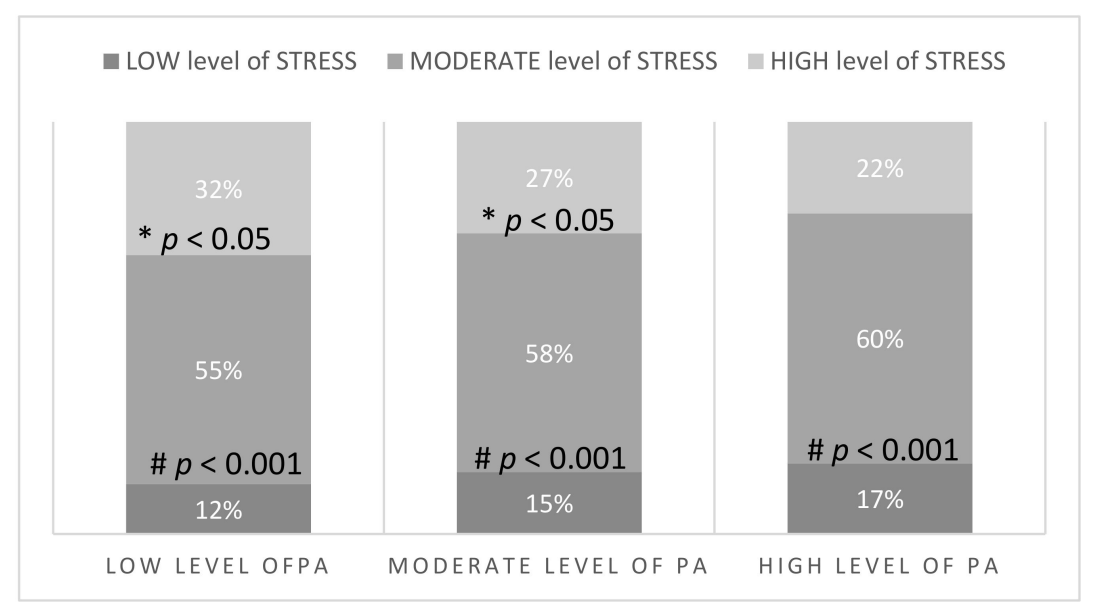

Figure 2. Number and the percentage of participants $(n=1956)$ with a specific level of stress depending on the level of PA. * $p$-value LOW vs. HIGH across different level of PA groups, \# $p$-value MODERATE vs. LOW and HIGH across different level of PA groups.
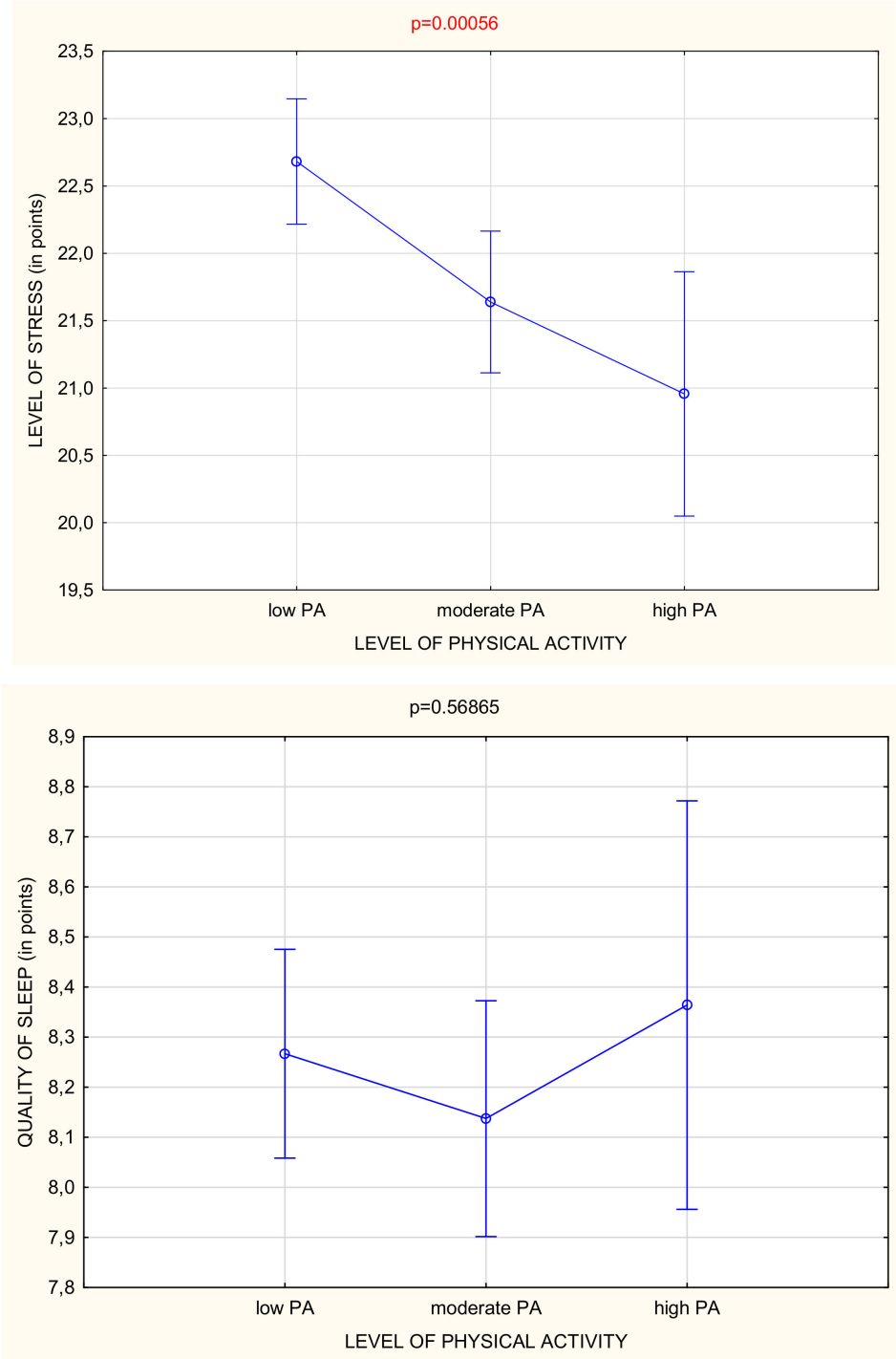

Figure 3. Level of stress and quality of sleep depending on the level of PA. 
Table 4. Time of physical activity according to the level of stress in the study population $(n=1956)$.

\begin{tabular}{cccc}
\hline \multirow{2}{*}{ PA and Stress } & $\begin{array}{c}\text { Low Level } \\
\text { of Stress }\end{array}$ & $\begin{array}{c}\text { Moderate Level } \\
\text { of Stress }\end{array}$ & $\begin{array}{c}\text { High Level } \\
\text { of Stress }\end{array}$ \\
\cline { 2 - 4 } & & Mean $( \pm$ SD) \\
\hline Total PA (min/day) & $51.71 \pm 36.43$ & $50.99 \pm 39.21$ & $44.99 \pm 36.10^{*}$ \\
Walking PA (min/day) & $29.83 \pm 30.47$ & $31.99 \pm 34.09$ & $29.01 \pm 31.99$ \\
Moderate PA(min/day) & $8.93 \pm 10.30$ & $8.34 \pm 9.69$ & $6.82 \pm 9.20 *$ \\
Vigorous PA (min/day) & $10.97 \pm 12.55$ & $9.72 \pm 11.99$ & $8.60 \pm 12.18^{*}$ \\
\hline${ }^{*} p<0.05$ High vs. Low and Moderate. & &
\end{tabular}

\subsection{Quality of Sleep in Relation to Physical Activity during Lockdown}

Over a half of the study participants reported poor quality of sleep (Table 2). People who declared a poor quality of sleep performed PA for $50.03 \pm 38.24 \mathrm{~min} /$ day on average, in comparison to those with good quality of sleep who undertook on average $48.04 \pm 37.60 \mathrm{~min} /$ day (Table 5). No difference was observed in the number of people with low and moderate levels of PA declaring a good quality of sleep, but there were also many highly active people with poor quality of sleep (Figure 4). It was observed that if the level of physical activity was moderate, the quality of sleep was better. However, too much physical activity can influence the quality of sleep negatively (Figure 3).

Table 5. Time of physical activity according to the quality of sleep in the study population $(n=1956)$.

\begin{tabular}{ccc}
\hline \multirow{2}{*}{ PA and Sleep Quality } & Poor Sleep Quality & Good Sleep Quality \\
\cline { 2 - 3 } & \multicolumn{2}{c}{ Mean $( \pm$ SD) } \\
\hline Total PA (min/day) & $50.03 \pm 38.24$ & $48.04 \pm 37.60$ \\
Walking PA (min/day) & $30.92 \pm 33.18$ & $30.63 \pm 32.73$ \\
Moderate PA (min/day) & $8.18 \pm 9.68$ & $7.61 \pm 9.61$ \\
Vigorous PA (min/day) & $9.94 \pm 12.27$ & $8.91 \pm 11.89$ \\
\hline
\end{tabular}

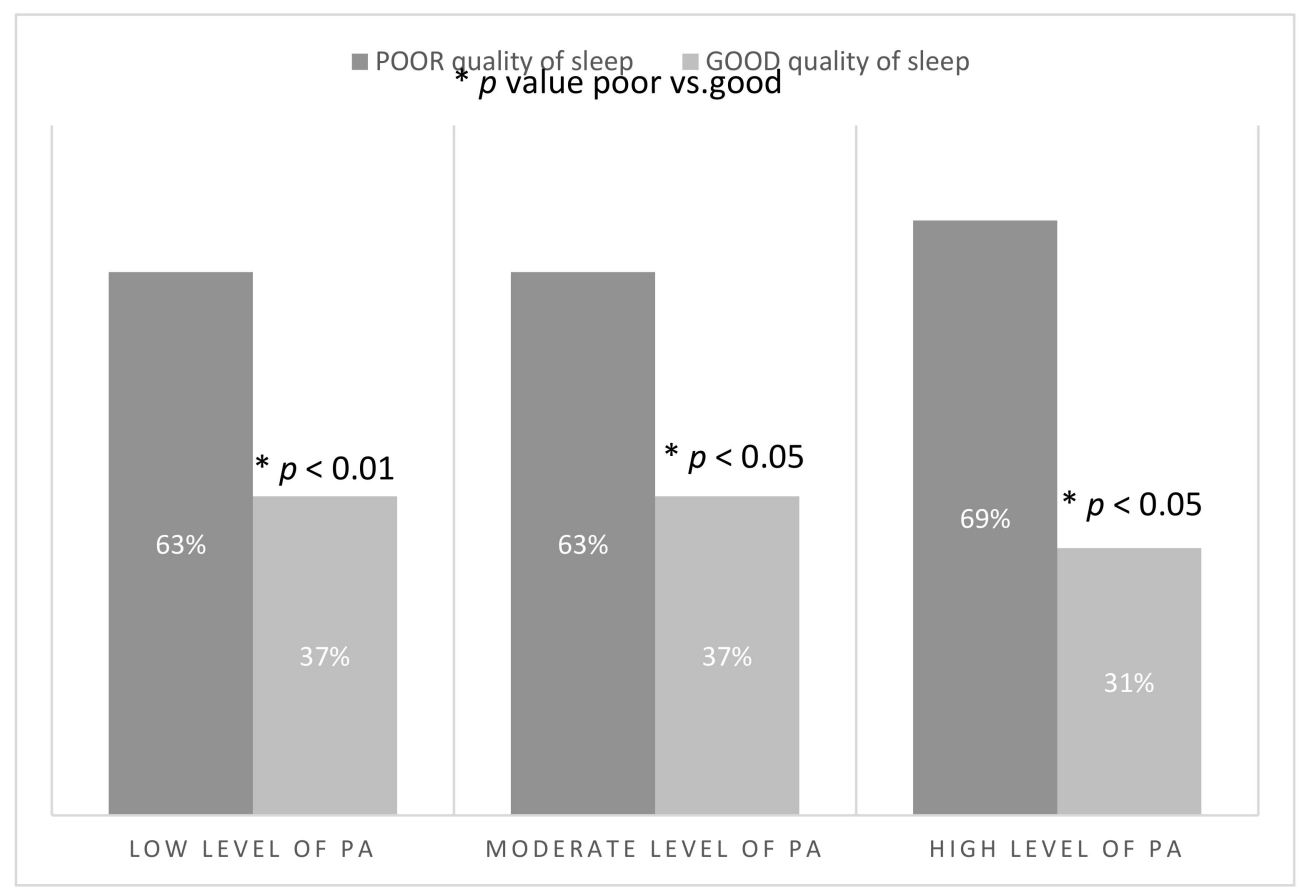

Figure 4. Number and the percentage of participants $(n=1956)$ with a specific quality of sleep depending on the level of PA. 


\subsection{Optimal Time and Intensity of PA during Lockdown}

Table 4 and Figure 3 show that the more time was spent on physical activity, the less stress the study participants experienced. However, it was also observed that too much PA during the day affected the quality of sleep (Figure 3). The linear correlation -0.523 also confirmed that there is a moderate negative relationship between PSS scores and the time of PA. It seems that the most favorable is a moderate level of physical activity, or performing about $70 \mathrm{~min} /$ day of habitual PA of different intensities (Table 3) to reduce stress and have a good quality of sleep (Figure 3). Apart from the amount of time devoted to physical activity, the intensity of the PA was also an important factor. There was no similar relationship observed for sleep quality (Table 4).

\section{Discussion}

Prolonged, harmful stress related to quarantine and limited social and physical contact with others could be a cause of serious mental disorders [22,23]. During the COVID-19 pandemic lockdown, the access to activities which decrease stress level such as work activities, interpersonal contact, physical activity or other hobbies was limited due to government restrictions implemented by governments in many countries. To our knowledge, this study was one of the first to have examined associations between stress, quality of sleep and limited physical activity after the implementation of social isolation rules during the COVID-19 pandemic lockdown.

The results of the study showed a high level of stress in most of the study participants. There are several reasons for stress during a pandemic, including the fear of the unknown, anxiety, prolonged uncertain situation, quarantine and limited contact with relatives and friends, lack of vaccines and medications for the virus, fear and high risk of contracting the virus, either by oneself or by family members, and also financial loss [23,24]. Studies in China $[9,25]$ during lockdown due to the COVID-19 pandemic evidenced that the intensity of the anxiety symptoms was associated with the worry about economic situation and stability of the family income. The enhanced perceived stress could also be explained by the fact that people who did not work during the pandemic were more exposed to information in the media, most of which was related to the pandemic, which contributed to accumulation of disturbing thoughts about the COVID-19 outbreak and its consequences [26] or fear of falling ill. It confirms that PA helps to decrease emotional and physical tension $[7,27,28]$, which leads to a decrease in stress level even during as stressful situation as the COVID-19 pandemic.

In the present study, most of the participants proved to have poor quality of sleep (QS). Sleep problems could be explained by the working time which drastically changed, especially for people working remotely because they work became quite irregular and dependent on the domestic environment. The influence of working time on sleep quality can be observed among healthcare workers who face the challenge of severe epidemic and insufficient time for rest, which results in chronic stress and psychological distress [26] and, consequently, to sleep disturbances. Poor quality of sleep can be related to stress as well as to circadian rhythm disruption, increasing the risk of severe metabolic disorders [29]. Additionally, the accumulation of intensive thinking about the COVID-19 pandemic could, in turn, lead to difficulties in falling asleep and a decrease in QS. However, again, the study participants who were engaged in physical activity reported their quality of sleep to be better than the inactive ones. A previous study demonstrated a correlation between sleep and physical activity [30] and revealed that regular PA improves QS [30].

One of the available studies showed that during lockdown, the study participants were inactive and spent most of their time watching TV or using other media tools $[3,24,31]$. An Italian study showed that energy expenditure on PA was significantly lower than before the pandemic in all age groups, especially among men [32]. A decrease of PA level was visible, especially among people with a high pre-pandemic activity level [33]. Other studies showed that the COVID-19 pandemic caused a decrease in PA level of each intensity (vigorous, moderate, walking and overall) and resulted in increased daily sitting 
time [34]. The decline of physical activity could be accounted for by social distancing, travel restriction, closure of gyms, swimming pools, amusement parks and green areas, i.e., places where PA was commonly performed prior to the COVID -19 pandemic [3]. A sudden PA level reduction could lead to numerous negative health consequences, especially metabolic diseases, cardiovascular diseases [35] and obesity, but could also cause mental disorders such as anxiety and depression [36] which altogether can increase the risk of COVID-19 infection and poor prognosis [37]. Some studies confirm that only regular, vigorous PA could decrease a high level of anxiety during the COVID-19 pandemic [38]. The present study revealed a low level of PA in almost half of the study participants.

To sum up, the study showed a lower SL and better QS during the COVID-19 pandemic lockdown in the participants who were engaged in PA. It should be recommended to undertake even the simplest forms of physical activity and use mobile technologies such as telephone applications and wearable sensors to encourage exercise [39]. There should be a moderate level of habitual PA obtained lasting about $70 \mathrm{~min} /$ day, and composed of PA of different intensities. The most beneficial duration of physical activity seems to be $40 \mathrm{~min} /$ day, as a combination of walking as well as moderate or vigorous PA.

There are a number of strengths of the present study, including a large sample size, the timing of data collection related to the lockdown in Poland and the usage of 3 internationally recognized tools $[17,19,20]$. However, some limitations should be acknowledged. Firstly, all the data are self-reported, which means that the responses are subject to recall bias, but it was the only manageable form of data collection during the pandemic-related restrictions [3,4]. There is socio-demographic information about the participants with no anthropometric and clinical data, but anthropometric data would have to be measured in direct contact, which was also impossible during the lockdown. Regarding the clinical data, there may have been concerns about giving too much medical data in an online questionnaire rather than in personal contact to the interviewer. Secondly, there was a higher response rate among women, however, most surveys conducted during the COVID19 pandemic suffered from an overrepresentation of the female gender $[4,40]$ as women appear to be more willing to complete this type of survey. Lastly, it was a cross-sectional observational study and more longitudinal data are needed to observe changes over time to assess the impact of social restrictions and social distancing on human health.

\section{Conclusions}

Our data suggest that the volume of physical activity can be a predictor of the level of stress and quality of sleep of adults during the COVID-19 pandemic lockdown. To retain a low level of stress and good quality of sleep, a lifestyle that allows to achieve a moderate level of physical activity should be maintained. The volume of recommended PA should be at least $70 \mathrm{~min}$ per day, involving different intensities. During the future pandemic restrictions, special attention should be paid to physical activity recommendations to improve the health status and well-being of society.

Author Contributions: Conceptualization, A.L.; methodology, A.L., P.R. and A.J.; software, A.L. and R.K.; validation, R.K.; formal analysis, A.L.; investigation, A.L. and P.R.; resources, K.K.; data curation, A.L., K.K. and K.M.; writing-original draft preparation, A.L. and K.M.; writing-review and editing, A.L. and D.T.; visualization, A.L.; supervision, A.J. and M.M.; project administration, A.L.; funding acquisition, M.M. All authors have read and agreed to the published version of the manuscript.

Funding: This research was financed from the EU-financed InterDoktorMen project (POWR.03.02.0000-I027/16).

Institutional Review Board Statement: Completing the questionnaire was anonymous and equivalent to agreeing to participate in the study, so the relevant University Human Ethics Committee decided to exempt it from the obligation of their approval.

Informed Consent Statement: Informed consent was obtained from all subjects involved in the study. 
Data Availability Statement: The data presented in this study are available on request from the corresponding author.

Acknowledgments: This research was conducted within the the EU-financed InterDoktorMen project (POWR.03.02.00-00-I027/16).

Conflicts of Interest: The authors declare no conflict of interest.

\section{References}

1. Stam, H.J.; Stucki, G.; Bickenbach, J. Covid-19 and Post Intensive Care Syndrome: A Call for Action. J. Rehabil. Med. 2020, 52, jrm00044. [CrossRef] [PubMed]

2. Zhuo, K.; Gao, C.; Wang, X.; Zhang, C.; Wang, Z. Stress and sleep: A survey based on wearable sleep trackers among medical and nursing staff in Wuhan during the COVID-19 pandemic. Gen. Psychiatr. 2020, 33, e100260. [CrossRef]

3. Stanton, R.; To, Q.G.; Khalesi, S.; Williams, S.L.; Alley, S.J.; Thwaite, T.L.; Fenning, A.S.; Vandelanotte, C. Depression, Anxiety and Stress during COVID-19: Associations with Changes in Physical Activity, Sleep, Tobacco and Alcohol Use in Australian Adults. Int. J. Environ. Res. Public Health 2020, 17, 4065. [CrossRef]

4. Lahav, Y. Psychological distress related to COVID-19-The contribution of continuous traumatic stress. J. Affect. Disord. 2020, 277, 12316. [CrossRef]

5. Taylor, S.; Landry, C.A.; Paluszek, M.M.; Fergus, T.A.; McKay, D.; Asmundson, G.J.G. COVID stress syndrome: Concept, structure, and correlates. Depress Anxiety 2020, 37, 706-714. [CrossRef] [PubMed]

6. Thomas, C.; Benzeval, M.; Stansfeld, S.A. Employment transitions and mental health: An analysis from the British household panel survey. J. Epidemiol Community Health 2005, 59, 243-249. [CrossRef] [PubMed]

7. Wang, C.; Pan, R.; Wan, X.; Tan, Y.; Xu, L.; McIntyre, R.S.; Choo, F.N.; Tran, B.; Ho, R.; Sharma, V.K.; et al. A longitudinal study on the mental health of general population during the COVID-19 epidemic in China. Brain Behav. Immun. 2020, 87, 40-48. [CrossRef] [PubMed]

8. Qiu, J.; Shen, B.; Zhao, M.; Wang, Z.; Xie, B.; Xu, Y. A nationwide survey of psychological distress among Chinese people in the COVID-19 epidemic: Implications and policy recommendations. Gen. Psychiatry 2020, 33, e100213. [CrossRef]

9. Otsuka, Y.; Kaneita, Y.; Itani, O.; Nakagome, S.; Jike, M.; Ohida, T. Relationship between stress coping and sleep disorders among the general Japanese population: A nationwide representative survey. Sleep Med. 2017, 37, 38-45. [CrossRef]

10. Xue, Z.; Lin, L.; Zhang, S.; Gong, J.; Liu, J.; Lu, J. Sleep problems and medical isolation during the SARS-CoV-2 outbreak. Sleep Med. 2020, 70, 112-115. [CrossRef]

11. Voulgaris, A.; Ferini-Strambi, L.; Steiropoulos, P. Sleep medicine and COVID-19. Has a new era begun? Sleep Med. 2020, 73, 170-176. [CrossRef]

12. Irwin, M.R.; Opp, M.R. Sleep Health: Reciprocal Regulation of Sleep and Innate Immunity. Neuropsychopharmacology 2017, 42, 129-155. [CrossRef]

13. Ainsworth, B.E.; Haskell, W.L.; Whitt, M.C.; Irwin, M.L.; Swartz, A.M.; Strath, S.J.; O’Brien, W.L.; Bassett, D.R., Jr.; Schmitz, K.H.; Emplaincourt, P.O.; et al. Compendium of physical activities: An update of activity codes and MET intensities. Med. Sci. Sports Exerc. 2000, 32, S498-S504. [CrossRef] [PubMed]

14. Rodriguez-Ayllon, M.; Cadenas-Sánchez, C.; Estévez-López, F.; Muñoz, N.E.; Mora-Gonzalez, J.; Migueles, J.H.; Molina-García, P.; Henriksson, H.; Mena-Molina, A.; Martínez-Vizcaíno, V.; et al. Role of Physical Activity and Sedentary Behavior in the Mental Health of Preschoolers, Children and Adolescents: A Systematic Review and Meta-Analysis. Sports Med. 2019, 49, 1383-1410. [CrossRef] [PubMed]

15. Ashdown-Franks, G.; Sabiston, C.M.; Stubbs, B. The evidence for physical activity in the management of major mental illnesses: A concise overview to inform busy clinicians' practice and guide policy. Curr. Opin. Psychiatry 2019, 32, 375-380. [CrossRef]

16. Bergier, J.; Kapka-Skrzypczak, L.; Biliński, P.; Paprzycki, P.; Wojtyła, A. Physical activity of Polish adolescents and young adults according to IPAQ: A population based study. Ann. Agric. Environ. Med. 2012, 19, 109-115. [PubMed]

17. Ainsworth, B.E.; Haskell, W.L.; Herrmann, S.D.; Meckes, N.; Bassett, D.R., Jr.; Tudor-Locke, C.; Greer, J.L.; Vezina, J.; Whitt-Glover, M.C.; Leon, A.S. The compendium of physical activities: A second update of codes and MET values. Med. Sci. Sports Exerc. 2011, 43, 1575-1581. [CrossRef] [PubMed]

18. IPAQ-Group. International Physical Activity Questionnaire; Cultural adaptation; IPAQ-Group. 2019. Available online: https: / / sites.google.com/site/theipaq/scoring-protocol (accessed on 20 May 2021).

19. Mollayeva, T.; Thurairajah, P.; Burton, K.; Mollayeva, S.; Shapiro, C.M.; Colantonio, A. The Pittsburgh sleep quality index as a screening tool for sleep dysfunction in clinical and non-clinical samples: A systematic review and meta-analysis. Sleep Med. Rev. 2016, 25, 52-73. [CrossRef]

20. Klein, E.M.; Brähler, E.; Dreier, M.; Reinecke, L.; Müller, K.W.; Schmutzer, G.; Wölfling, K.; Beutel, M.E. The German version of the Perceived Stress Scale-Psychometric characteristics in a representative German community sample. BMC Psychiatry 2016, 16, 159. [CrossRef]

21. Baik, S.H.; Fox, R.S.; Mills, S.D.; Roesch, S.C.; Sadler, G.R.; Klonoff, E.A.; Malcarne, V.L. Reliability and validity of the Perceived Stress Scale-10 in Hispanic Americans with English or Spanish language preference. J. Health Psychol. 2019, 24, 628-639. [CrossRef] 
22. Hull, H.F. SARS control and psychological effects of quarantine, Toronto, Canada. Emerg. Infect. Dis. 2005, 11, 354-355. [CrossRef] [PubMed]

23. Brooks, S.K.; Webster, R.K.; Smith, L.E.; Woodland, L.; Wessely, S.; Greenberg, N.; Rubin, G.J. The psychological impact of quarantine and how to reduce it: Rapid review of the evidence. Lancet 2020, 395, 912-920. [CrossRef]

24. Losada-Baltar, A.; Jiménez-Gonzalo, L.; Gallego-Alberto, L.; Pedroso-Chaparro, M.D.S.; Fernandes-Pires, J.; Márquez-González, M. "We're staying at home". Association of self-perceptions of aging, personal and family resources and loneliness with psychological distress during the lock-down period of COVID-19. J. Gerontol. 2020. [CrossRef]

25. Cao, W.; Fang, Z.; Hou, G.; Han, M.; Xu, X.; Dong, J.; Zheng, J. The psychological impact of the COVID-19 epidemic on college students in China. Psychiatry Res. 2020, 287, 112934. [CrossRef]

26. Huang, Y.; Zhao, N. Generalized anxiety disorder, depressive symptoms and sleep quality during COVID-19 outbreak in China: A web-based cross-sectional survey. Psychiatry Res. 2020, 288, 112954. [CrossRef]

27. Fletcher, G.F.; Landolfo, C.; Niebauer, J.; Ozemek, C.; Arena, R.; Lavie, C.J. Promoting Physical Activity and Exercise: JACC Health Promotion Series. J. Am. Coll. Cardiol. 2018, 72, 1622-1639. [CrossRef] [PubMed]

28. Dominski, F.H.; Brandt, R. Do the benefits of exercise in indoor and outdoor environments during the COVID-19 pandemic outweigh the risks of infection? Sport Sci. Health 2020, 1-6. [CrossRef]

29. Rizza, S.; Luzi, A.; Mavilio, M.; Ballanti, M.; Massimi, A.; Porzio, O.; Magrini, A.; Hannemann, J.; Menghini, R.; Lehrke, M.; et al. Alterations in Rev-ERB $\alpha / B M A L 1$ ratio and glycated hemoglobin in rotating shift workers: The EuRhythDia study. Acta Diabetol. 2021. [CrossRef]

30. Mead, M.P.; Baron, K.; Sorby, M.; Irish, L.A. Daily Associations Between Sleep and Physical Activity. Int. J. Behav. Med. 2019, 26, 562-568. [CrossRef] [PubMed]

31. Matias, T.; Dominski, F.H.; Marks, D.F. Human needs in COVID-19 isolation. J. Health Psychol. 2020, 25, 871-882. [CrossRef]

32. Maugeri, G.; Castrogiovanni, P.; Battaglia, G.; Pippi, R.; D'Agata, V.; Palma, A.; Di Rosa, M.; Musumeci, G. The impact of physical activity on psychological health during Covid-19 pandemic in Italy. Heliyon 2020, 6, e04315. [CrossRef]

33. Castañeda-Babarro, A.; Arbillaga-Etxarri, A.; Gutiérrez-Santamaría, B.; Coca, A. Physical Activity Change during COVID-19 Confinement. Int. J. Environ. Res. Public Health 2020, 17, 6878. [CrossRef] [PubMed]

34. Ammar, A.; Brach, M.; Trabelsi, K.; Chtourou, H.; Boukhris, O.; Masmoudi, L.; Bouaziz, B.; Bentlage, E.; How, D.; Ahmed, M.; et al. Effects of COVID-19 Home Confinement on Eating Behaviour and Physical Activity: Results of the ECLB-COVID19 International Online Survey. Nutrients 2020, 12, 1583. [CrossRef] [PubMed]

35. Lippi, G.; Henry, B.M.; Sanchis-Gomar, F. Physical inactivity and cardiovascular disease at the time of coronavirus disease 2019 (COVID-19). Eur. J. Prev. Cardiol. 2020, 27, 906-908. [CrossRef]

36. Conn, V.S. Anxiety outcomes after physical activity interventions: Meta-analysis findings. Nurs. Res. 2010, 59, 224-231. [CrossRef] [PubMed]

37. Rizza, S.; Coppeta, L.; Grelli, S.; Ferrazza, G.; Chiocchi, M.; Vanni, G.; Bonomo, O.C.; Bellia, A.; Andreoni, M.; Magrini, A.; et al. High body mass index and night shift work are associated with COVID-19 in health care workers. J. Endocrinol. Investig. 2021, 44, 1097-1101. [CrossRef]

38. Meira, C.M., Jr.; Meneguelli, K.S.; Leopoldo, M.P.G.; Florindo, A.A. Anxiety and Leisure-Domain Physical Activity Frequency, Duration, and Intensity During Covid-19 Pandemic. Front. Psychol. 2020, 11, 603770. [CrossRef] [PubMed]

39. Crisafulli, A.; Pagliaro, P. Physical activity/inactivity and COVID-19. Eur. J. Prev. Cardiol. 2020. [CrossRef]

40. Lai, J.; Ma, S.; Wang, Y.; Cai, Z.; Hu, J.; Wei, N.; Wu, J.; Du, H.; Chen, T.; Li, R.; et al. Factors Associated With Mental Health Outcomes Among Health Care Workers Exposed to Coronavirus Disease 2019. JAMA Netw. Open 2020, 3, e203976. [CrossRef] [PubMed] 